\title{
REFLEXÃO SOBRE PARTICIPAÇÃO SOCIAL: BARREIRAS E ESTRATÉGIAS
}

\author{
Camila Balista Garbeline ${ }^{1}$
}

\begin{abstract}
Resumo: A participação social é uma consolidação do processo democrático no fortalecimento da cidadania. Entretanto muitas conduções da participação são amadoras, observam-se longos debates onde os problemas principais estão mascarados, ganhando destaque os temas que as forças econômicas e políticas desejam salientar. O objetivo geral do trabalho é um aporte teórico-metodológico sobre a participação social, como está sendo tratada pelos gestores e pela sociedade civil em diferentes países. Foram pesquisados artigos como base teórica-metodológica de acordo com o tema da pesquisa, dos 64 artigos encontrados considerando o local e ano de publicação, foram utilizados $40 \mathrm{com}$ estudos de caso em diferentes países, como nos Estados Unidos, China, Índia, Japão entre outros. Os artigos salientam as barreiras encontradas na participação social e outros quatro estudos de caso mostram uma participação social com poder de influenciar decisões.
\end{abstract}

Palavras-chave: Reflexão crítica; Participação social; Democracia; Interesses

\section{CRITICAL REFLECTION ON SOCIAL PARTICIPATION: BARRIERS AND STRATEGIES}

\begin{abstract}
Social participation is a consolidation of the democratic process in strengthening citizenship. However, many of the participatory approaches are amateurish. There are long debates where the main problems are masked, highlighting the themes that the economic and political forces wish to emphasize. The general objective of the work is a theoreticalmethodological contribution on social participation, as it is being handled by managers and civil society in different countries. The articles were searched as a theoretical and methodological basis according to the theme of the research. Of the 64 articles found considering the place and year of publication, 40 were used with case studies in different countries, such as the United States, China, India, Japan, and others. The articles highlight the barriers encountered in social participation and four other case studies show a social participation with power to influence decisions.
\end{abstract}

Keywords: Critical reflection; Social participation; Democracy; Interests

\section{REFLEXIÓN SOBRE PARTICIPACIÓN SOCIAL: BARRERAS Y ESTRATEGIAS}

Resumen: La participación social es una consolidación del proceso democrático en el fortalecimiento de la ciudadanía. Sin embargo, muchas conductas de la participación son aficionadas, se observan largos debates donde los problemas principales están enmascarados, ganando destaque los temas que las fuerzas económicas y políticas desean subrayar. El objetivo general del trabajo es un aporte teórico-metodológico sobre la participación social, como está siendo tratada por los gestores y la sociedad civil en diferentes países. Se han investigado artículos como base teórica-metodológica de acuerdo con el tema de la investigación, de los 64 artículos encontrados considerando el local y el año de publicación, se utilizaron 40 con estudios de caso en diferentes países, como en los Estados Unidos, China,

\footnotetext{
${ }^{1}$ Camila Balista Garbeline - UnB/Doutoranda em Geografia. Email: camila.garbel@gmail.com
} 
India, Japón entre Otros. Los artículos subrayan las barreras encontradas en la participación social y otros cuatro estudios de caso muestran una participación social con poder de influir en las decisiones.

Palabras clave: Reflexión crítica; Participación social; Democracia; Intereses

\section{INTRODUÇÃO}

São vários os conceitos de participação social que existem na literatura. Afinal, é um conceito amplo, com dificuldades práticas de operacionalização, mas abordados em projetos de planejamentos. Participação ou participação social diz respeito à construção de espaços que criam interconexões entre os gestores e a sociedade (CARVALHO, 1998). A participação é uma conquista da sociedade, significa uma busca pela democratização, e tem significado histórico para países que viveram em regimes autoritários, pela luta a participação tornou-se um direito do cidadão.

Para uma participação deve ocorrer a oportunidade de dividir responsabilidades e promover o conhecimento da sociedade. Assim, no planejamento urbano-ambiental a participação social deveria ocorrer passo a passo com os estudos de planejamento, os agentes sociais deveriam estar envolvidos nos temas e nos indicadores socioambientais, mas tal processo não ocorre na prática.

A participação social raramente é reconhecida, esse é o principal problema abordado por vários autores, prevalecem sobre a opinião da população os objetivos das partes interessadas, sejam elas políticas ou econômicas. Assim, a participação da sociedade enfrenta dificuldades como a deficiência no sistema legal, manipulação de interesses econômicos, e a quase inexistente divulgação de informações referentes à participação social, o que é uma participação social, a percepção da sociedade civil, a noção que podem participar e expor as opiniões referentes aos assuntos abordados.

Percebe-se nas leituras e nos estudos de caso que muitas conduções das participações sociais são amadoras, observam-se longos debates onde os problemas principais estão mascarados, ganhando destaque os temas que as forças econômicas e políticas desejam salientar. Mostram velhas questões com novas roupagens. Santos (2004) comenta que é comum o planejador ter fortes resistências às mudanças em função da manipulação feita pelo mercado/interesses.

Estudos apontam que tem havido a obrigação da realização de audiências públicas, porém, o fato de existir a realização de audiências com a participação social não garante a 
qualidade da participação, não garante a real inserção da população em decisões sobre projetos urbanos e ambientais. A participação se aplica nas últimas etapas dos projetos de planejamento, sem tempo ou amadurecimento suficiente para uma decisão.

A lógica da participação social tem sido amplamente documentada em vários países devido à importância de aumentar a consciência e conhecimento da população sobre o direito e dever de expor suas ideias e de ter voz diante das mudanças. Mesmo em países onde o poder de decisão está concentrado numa parcela minoritária da população, hoje a participação social quando levada a sério, ao ponto de ser ouvida, significa poder nas mãos dos que por muitos anos foram excluídos das decisões.

Diante do exposto o objetivo geral do trabalho é um aporte teórico-metodológico sobre a participação social, como está sendo tratada e gerenciada pelos gestores de diferentes países. Seguido pelos objetivos específicos, são eles: como a participação social foi tratada nos últimos 40 anos; analise de vários artigos de diferentes países que abordam o tema proposto; os estudos de caso que a sociedade civil na participação social foi considerada como ativa nas decisões sobre a implementação dos empreendimentos; as barreiras que inibem a participação social; a importância da participação social e as mudanças apresentadas pelos autores.

Nesse contexto, o artigo aborda um estudo de revisão bibliográfica realizado como parte das etapas do estudo de tese, portanto, foram incluídos artigos de alto impacto, estudos de caso e relatos de experiência que abarcassem o tema e a metodologia para analisar a participação social em tomadas de decisão. Tais estudos estão publicados no idioma inglês e esloveno.

Foram realizadas leituras com estudos de caso na China, Estados Unidos, Japão, Brasil, entre outros países. Na leitura dos artigos os autores comentam a necessidade de continuar os estudos sobre a participação social, a sociedade pode decidir o melhor rumo a ser seguido quando se tem a real inserção da população nas tomadas de decisão.

Nesse contexto, o presente trabalho teve como foco descrever e analisar os artigos científicos encontrados no periódico da capes, desta forma, elaborar uma reflexão crítica sobre como está sendo tratada a participação social pelo mundo.

\section{Participação Social}

A participação social na política ambiental e urbana é um importante processo nos últimos anos. Participação ou participação social diz respeito à construção de espaços que criam interconexões entre os gestores e a sociedade (CARVALHO, 1998). 
De acordo com alguns autores como Carvalho (1998) e Santos (2004) a participação pode assumir distintos formatos organizativos, como: movimentos populares, partidos, sindicatos, organizações não governamentais, enfim, os conjuntos dos representantes são de base social, política e econômica.

As primeiras práticas de urbanismo democrático aconteceram nos Estados Unidos em 1960, ou seja, práticas que buscavam defender as reivindicações da classe mais desfavorecida (NUNES, 2006).

No Brasil, segundo Bava (2003) no ano de 1970 iniciou a tentativa de aplicar a gestão participativa a fim de melhorar as precárias condições de vida da população desamparada. A gestão participativa estimularia organizações populares como a associação de moradores. Essas são notas que apontam para solução de problemas urbano-ambientais por meio de construção de uma nova política democrática, a população como instrumento dos atores do sistema de gestão, e como voz ativa para as mudanças.

Em relação à participação em processos ambientais, destaca-se a Conferência de Estocolmo, realizada em 1972, que teve início o processo da participação social nas decisões governamentais concernentes ao meio ambiente e o reconhecimento de que a sociedade precisava ser informada sobre as problemáticas e participar na preservação do meio ambiente. Desde então, a participação social passou a fazer parte da gestão do meio ambiente. $\mathrm{Na}$ segunda conferência ambiental, Rio-92 a participação social recebeu status de princípio, foi o tema mais debatidos (ASSUNÇÃO, 2006).

No planejamento urbano-ambiental a participação social apresenta avanços, uma conquista social foi a Constituição Federal de 1988. A década de 1980 foi marcada por conquistas, no sentido da luta pela população civil para serem considerados como agentes ativos em todos os tipos de decisões. O retorno das eleições diretas em 1985, a luta pela Reforma Urbana, e a Constituição de 1988, fazendo com que os conceitos de participação e cidadania andassem lado a lado.

A Constituição Federal de 1988 é o marco da legalidade da questão social, um avanço na gestão das cidades, uma nova forma que na teoria exibe que o poder de decisão não mais se restringe a pequenos grupos com poder econômico e político, mas também a sociedade civil.

Nunes (2006) afirma que num país onde o poder de decisão foi monopolizado pela elite econômica, a participação social significa uma democratização de poder. Desta forma, a participação passa a ser um referencial da ampliação do acesso de setores populares, como fortalecimento de mecanismos democráticos. 
Na Constituição Federal, no Capítulo da Política Urbana, nos artigos 182 e 183, onde definem que o Plano Diretor é um instrumento obrigatório para determinados municípios, é uma conquista, pois estabelece a função social da cidade, com direto a moradia, a infraestrutura, saneamento básico, de forma participativa e igualitária. Para Villaça (2005) os debates públicos em torno do Plano Diretor representam um avanço muito pequeno em relação à prática social, que é a prática popular em si. Em primeiro lugar, anteriormente havia pouquíssima participação social, diante de zero, qualquer crescimento é ilimitado. Em segundo, porque em termos de pressão econômica e política sobre os gestores, a da minoria foi enorme, e a maioria limitadíssima. Ou seja, Villaça (2005) mostrou que a pressão da elite ainda permanece como agente ativo, os tomadores de decisão, e a maioria, essa "maioria" retrata o povo que não tem o poder diante das decisões, continua sendo agente passivo.

Percebe-se que a participação social é um conceito amplo, com dificuldades práticas de operacionalização. Mas a participação social é um dos pilares do processo de construção da democracia, deveria ser uma sociedade civil com voz ativa, tratados como agentes ativos em decisões.

Boas práticas de participação social são caracterizadas por aquelas em que todas as partes interessadas são incluídas, a informação é compartilhada de forma aberta e a vontade de encontrar soluções é de interesse mútuo (FINSON et al., 2005).

Santos (2004) disserta sobre os diferentes tipos e graus de participação, mas serão tratadas apenas três tipologias da participação, são elas: Participação Manipulada; Participação Passiva; e Participação Interativa. O autor diferencia os três tipos de participação. O primeiro, a participação manipulada, seria uma participação aparente, os quais não tem o poder de decisão. A segunda, a participação passiva, as pessoas participam tomando conhecimento do que já foi decidido ou feito, assim não tem a devida atenção às respostas das pessoas. E o terceiro, a participação interativa, as pessoas participam, a participação é vista como um direito e não como um meio de alcançar metas de projeto, assim, os grupos locais tomam o controle sobre as decisões.

Para Gohn (2005) a participação pode ser analisada em três níveis básicos: o

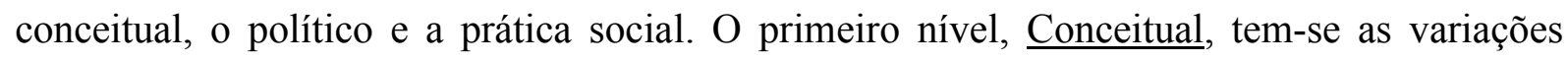

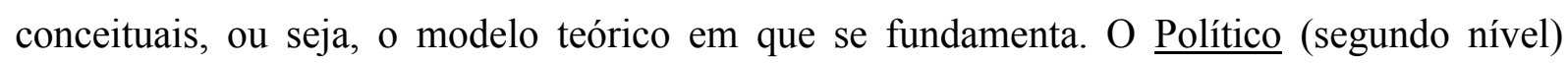
depende do estágio democrático em que a sociedade se encontra, ou seja, se está em luta para a sua aquisição ou em processo de consolidação. E a Prática Social (terceiro nível), isto é, os movimentos de participação, as associações e organizações. 
Assim, os níveis de participação social podem evoluir para formas mais democráticas, ou retroceder, dependendo de como a sociedade movimenta-se para lutar por esse direito. A sociedade dos países em desenvolvimento ainda está aprendendo a lutar e reivindicar direitos de participação em decisões públicas.

O principal desafio para a participação é criar uma forma mais ativa de representatividade, isso implicaria numa redistribuição de poder, para que as pessoas não sejam apenas ouvidas, a informação coletava deve ser incorporada no processo de decisão.

A vantagem associada à participação é a possibilidade das pessoas afetadas pelas decisões fazerem-se presentes e por ser um mecanismo de troca de informações, assim, a participação permite que os órgãos responsáveis pelas decisões sejam sensíveis para aspectos que vão além do próprio projeto. Entretanto, Canter (1998) comenta que existem desvantagens associadas às atividades de participação, como: a chance de ter uma informação errônea entre os participantes, o conhecimento pode ser limitado sobre as questões tratadas, incerteza dos resultados. Mas deve-se lembrar de que a incerteza faz parte dos processos democráticos, e sendo considerada como desvantagem compromete a natureza da democracia.

A situação ideal é que a participação seja ativa, tenha autocrítica, mas percebe-se que a participação social ainda perpassa sobre as participações manipuladas e passivas, a participação social ainda é vista como um obstáculo, apenas uma obrigação a ser seguida por lei, desta forma, a participação social é raramente reconhecida.

O Estado tem um papel primordial no incentivo da participação, inclusive na divulgação de informações para uma participação ativa e crítica, mas para isso o crescimento econômico não pode ser o único objetivo a influenciar as decisões governamentais, os gestores precisam tomar como etapa decisória a opinião da sociedade civil para depois decidir o melhor rumo a seguir. E a população deve lutar por seus direitos, mais adiante serão demonstrados exemplos de uma participação ativa, onde a sociedade civil influenciou nas decisões finais de projetos que podem prejudicar o bem estar social e ambiental.

Contudo, estudos apontam que tem havido a obrigação da realização de audiências públicas, porém, o fato de existir a realização de audiências com a participação social não garante a qualidade da participação, não garante a real inserção da população em decisões sobre projetos urbanos e ambientais. A participação se aplica nas últimas etapas dos projetos de planejamento, sem tempo ou amadurecimento suficiente para uma decisão.

A lógica da participação social tem sido amplamente documentada em vários países devido à importância de aumentar a consciência da população sobre o direito e dever de expor 
suas ideias e de ter voz diante das mudanças. Mesmo em países onde o poder de decisão está concentrado numa parcela minoritária da população, hoje a participação social quando levada a sério, ao ponto de ser ouvida, significa poder nas mãos dos que por muitos anos foram excluídos das decisões.

Outra forma de poder e de conscientização da população diante dos problemas socioambientais é a educação ambiental crítica, pois ela promove um questionamento crítico as abordagens reducionistas em relação à economia, a natureza e a sociedade. Assim, a educação ambiental crítica auxilia na luta pelos direitos, quando a educação é crítica ela visa analisar os problemas socioambientais em sua raiz, de forma holística, e não mais uma análise reducionista ou com tendências ideológicas do sistema dominante.

Uma educação crítica é voltada para o exercício da cidadania, a sociedade adquire percepção, com isso pode participar de forma efetiva das decisões que os afetam, e lutar por seus direitos.

A educação ambiental pode proporcionar o desenvolvimento de um posicionamento crítico, fazendo com que os cidadãos se tornem capazes de analisar os fatores implícitos e explícitos da realidade política, econômica, social e ambiental, propondo alternativas aos problemas.

\section{Balanço da Participação Social em Diferentes Países}

Com o objetivo de avançar no conhecimento sobre a participação social na gestão urbanaambiental, foram pesquisados artigos como base teórica- metodológica de acordo com o tema da pesquisa, dos 64 artigos encontrados considerando o local e ano de publicação, foram utilizados 40, dois foram de estudos na Alemanha, quatro no Brasil, um no Chile, sete na China, um na Eslovênia, um na Espanha, onze nos Estados Unidos, um na Grã Bretanha, um na Índia, dois na Inglaterra, um no Irã, dois no Japão, um na Malásia, um na Polónia, dois no Reino Unido, um na Suécia, um na Tailândia.

No aporte teórico-metodológico percebe-se que o assunto referente ao tema de participação social tem os maiores índices de publicação no período de 2008 a 2016, pode ser devido a percepção da grave situação ambiental em que o mundo se encontra, e também a força dos movimentos sociais atualmente, diferente de 50 anos atrás, quando a população não tinha consciência dos seus direitos e deveres.

Percebe-se após a leitura em alguns artigos que o valor instrumental de participação social gera benefícios na tomada de decisão dos processos. O autor Craig et al. (2012) comenta que 
ao incorporar diversas perspectivas, a participação pode auxiliar nos pontos que seriam negligenciados, desta forma, melhora a gestão.

Entretanto, pode-se dizer que tem havido uma obrigação da realização em audiências de participação social. Um exemplo é a avaliação da participação social em alguns países dos Estados Unidos, os pesquisadores comentam que a participação da população civil é vista como um obstáculo, não é considerada um apoio relevante nas decisões de implementação dos empreendimentos.

Contudo, um estudo de caso realizado na Califórnia (Estados Unidos) mostrou que a influência nas escolas sobre a questão ambiental aumentou a participação dos pais dos alunos e os próprios adolescentes em projetos ambientais.

Os programas de Educação Ambiental voltado para toda a sociedade com vista a conscientizá-los sobre situação ambiental, a degradação do meio ambiente pelo imediatismo das forças econômicas é importante. No entanto, ações específicas são necessárias para levar até os moradores noções educativas ambientais, assim como, o direito e o dever de participar das audiências públicas e lutar pela melhora socioambiental diante das forças econômicas. Vale lembrar que ao realizar as ações de luta pelos direitos, os participantes projetam um sentimento de pertencimento social, passam a se sentir como um grupo ativo.

Outros três artigos trazem uma participação social com voz ativa nas decisões de implementação dos empreendimentos, como: Na China, um estudo de caso realizados com os protestos NIMBYism, em vários projetos o governo considerou a opinião da sociedade civil nas audiências públicas e foi realizado o que a maioria dos indivíduos gostariam, essa atitude foi tomada por medo dos propostos em outros projetos; Na Alemanha, o estudo de caso mostrou como a participação contribuiu para condições mais favoráveis na implementação dos empreendimentos; Na Grã-Bretanha, o estudo de caso ilustrou como projetos junto a sociedade civil melhorou as decisões sobre as obras dos empreendimentos.

A participação é raramente reconhecida, mas tem que ser algo significativo, ao ponto de influenciar decisões como mostram esses quatro artigos citados, mas para que ocorra, a população tem que se mobilizar e lutar pela democratização do poder.

Outro aspecto que os autores expõem nos artigos são as barreiras que inibem uma participação social ativa, as principais barreiras, são: pouco conhecimento sobre a importância ambiental, falta de informação sobre a legislação, incapacidade de influenciar o processo de tomada de decisão, falta de conhecimento sobre a participação social, o não saber do direito 
de participação, má execução da participação pela população, falta de conhecimento para acessar sites onde contem os documentos e informações das audiências públicas.

A falta de conhecimento vinculada a longos documentos carregados com termos técnicos intimidam ainda mais a população que não tem um conhecimento técnico, desta forma, não tem a oportunidade de expressar opiniões por falta de informações e conhecimentos.

Uma participação social ideal seria aquela que o cidadão não é visto como obstáculos. Craig et al. (2012) comenta sobre a ideia de igualdade das pessoas dentro do arranjo político, essa igualdade implica que a população tem o direito de participar da vida política, cada pessoa deve ter a oportunidade de participar das decisões que os afetam, bem como aqueles em que dizem respeito ao bem social.

Outras análises realizadas nos artigos foram às palavras que permeiam a participação social, são elas: "barreiras" e "conflitos", elas dificultam uma participação social ativa nas decisões finais (Figura 1).

Compreende-se que a participação social é um dos pilares do processo de construção da democracia, mas ainda enfrenta barreiras para ser reconhecida como algo significativo ao ponto de influenciar decisões sobre projetos a serem implementados. Sendo comum o planejador ter fortes resistências às mudanças em função da manipulação feita por grupos de interesse, ganham destaque os temas que as forças econômicas desejam salientar. Desta forma, percebe-se que a participação social tem dificuldades práticas de operacionalização.

Entretanto, mesmo com as barreiras na participação, foram elucidados quatro estudos de caso que mostram uma participação social ativa, com poder de influenciar decisões, mas percebe-se uma população que se mobiliza para exigir seus direitos, mostra que a participação social pode ter voz ativa, mas é preciso uma organização por parte da população para garantir o poder de decisão.

Figura 1 - Palavras que permeiam a participação social

Participação Social

Democratização do poder 


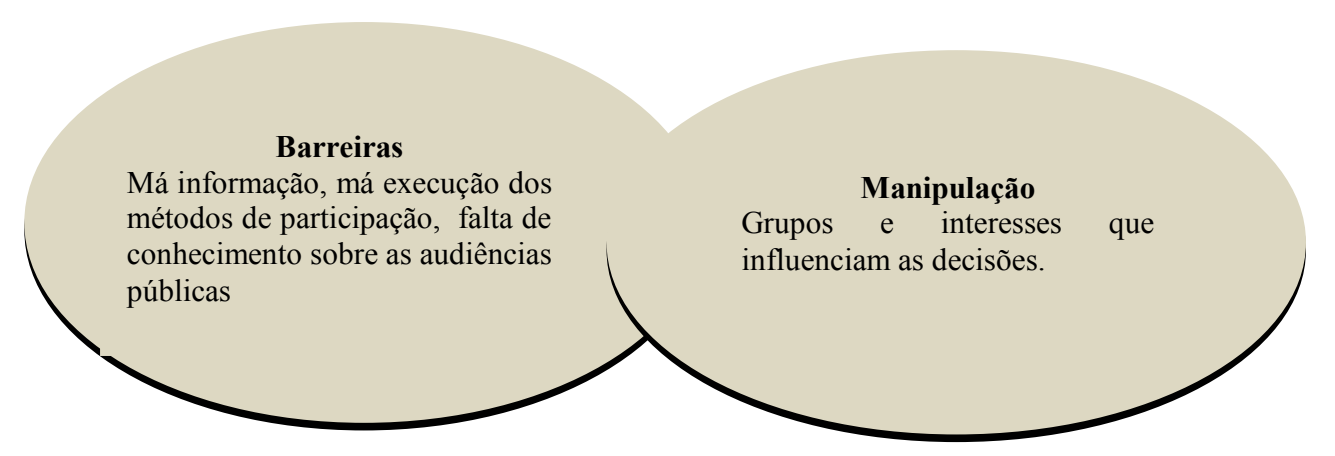

Elaboração: GARBELINE, C. B., 2016

Figura 2 - Elementos de Participação

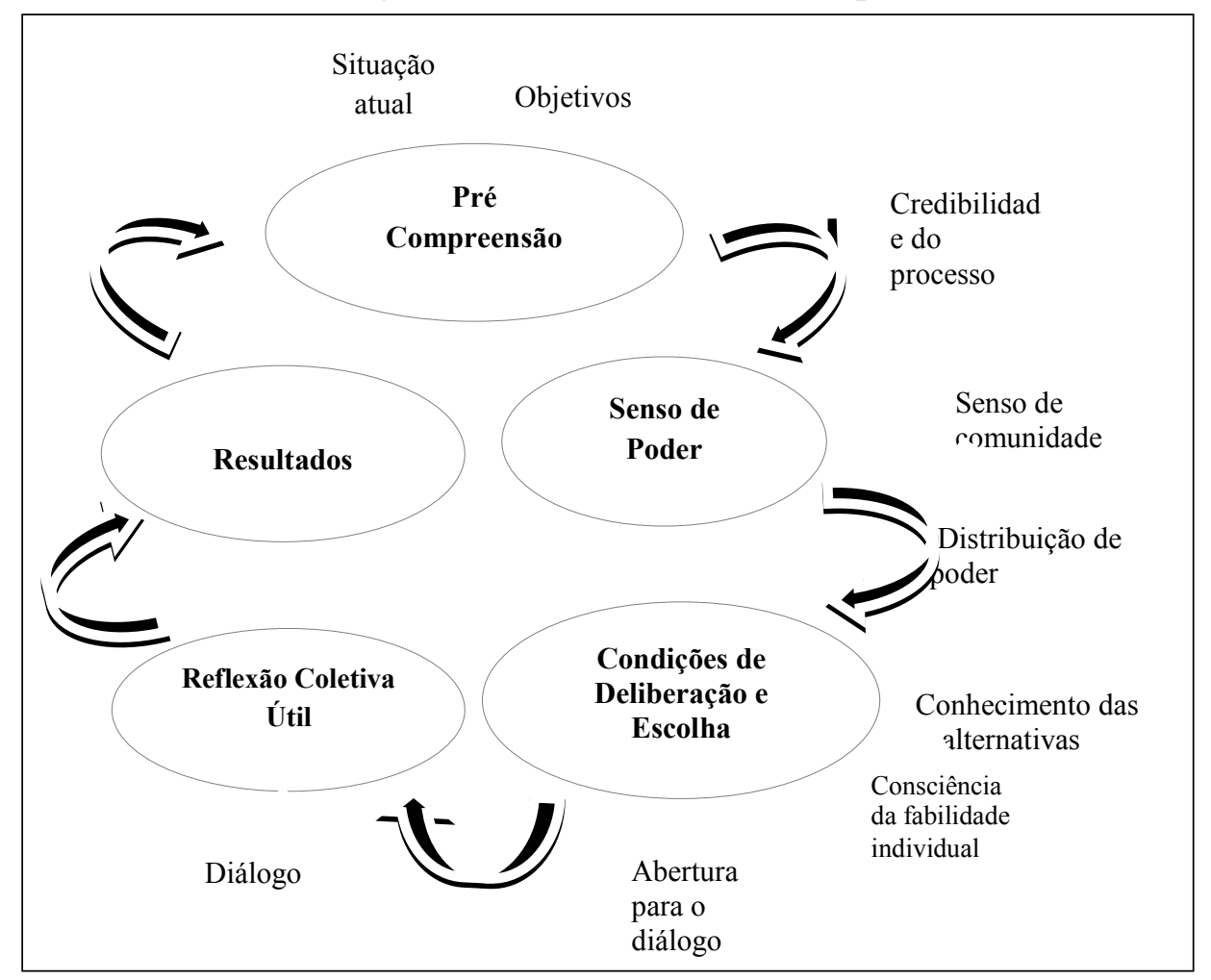

Fonte: Scarabello Filho, 2003 apud Santos, 2004. p. 160

O ideal é que a sociedade civil tenha capacidade de entender os relatórios para fazer uma autocrítica sobre os problemas que se encontram, mas também o senso comum (Figura 2) que cada participante tem sobre determinada área e/ou tema devem ser levados em consideração, o somatório de todos os elementos da participação levam a uma reflexão coletiva por meio de diálogos e decisões. 
Compreende-se que a participação social é um dos pilares do processo de construção da democracia, mas ainda enfrenta barreiras para ser reconhecida como algo significativo ao ponto de influenciar decisões sobre projetos.

Os níveis de participação podem evoluir para formas mais democráticas dependendo de como a sociedade movimenta-se para lutar por esse direito. Uma participação social ideal seria aquela que o cidadão não é visto como obstáculos, pelo contrário, deve ter a oportunidade de uma participação direta, e o poder de diálogo e decisão deve estar também sobre a população. Como lembra Canter (1998), não basta que as pessoas sejam ouvidas, é preciso incorporar a informação no processo decisório.

De forma geral, a participação ainda é manipulada pela minoria e passiva pelo povo (a maioria). A questão que fica é como minimizar os impactos socioambientais sem a devida participação da sociedade? Os interesses econômicos não visam a qualidade de vida, visam o lucro.

\section{Considerações Finais}

Ao estudar a história da participação social percebe-se que no passado a participação social era igual à zero, e qualquer número perto de zero parece melhor. Houve um crescimento da participação nos dias de hoje, mas como já foi dito qualquer número perto de zero parece bom, mas ainda é limitado. Assim tem-se uma minoria como agentes ativos, com pressão sobre as decisões, e a maioria que é considerada o povo, mas essa maioria tem um número ainda limitado e continua como agente passivo.

A partir da análise sobre a participação social, pode-se falar sobre os três tipos de participações, são elas: a participação manipulada, uma participação aparente, os quais não tem o poder de decisão; a participação passiva, as pessoas participam tomando conhecimento do que já foi decidido ou feito, assim não tem a devida atenção às respostas dos indivíduos; e a participação interativa, as pessoas participam, a participação é vista como um direito e não como um meio de alcançar metas de projeto, assim, as comunidades locais tomam o controle sobre as decisões.

A situação ideal seria uma participação ativa com redistribuição do poder, mas percebe-se que a participação social ainda perpassa sobre as participações manipuladas e passivas, a participação social ainda é vista como um obstáculo, apenas uma obrigação a ser seguida por lei, desta forma, é raramente reconhecida. Muitas vezes tem a finalidade de apenas recolher informações, a sociedade reage em relação a um projeto, fazem comentários e 
recomendações, mas cabe a equipe técnica do órgão competente crer relevante ou não as informações.

A participação por manipulação atende aos interesses de grupos econômicos. Mas a participação pela reivindicação, que consiste em afirmar uma posição, a reivindicação de grupos ambientais ou da própria sociedade civil que conseguem apoio da mídia (site, televisão, rádio) obtêm uma repercussão maior, o que contribui para o fortalecimento dos grupos, por fim conseguem inserir suas demandas como prioridade nos projetos. Contudo, os grupos econômicos e políticos contribuem para a utilização dos métodos de persuasão e ressarcimento da população, de tal modo, comprometem a participação ativa dos indivíduos na tomada de decisão.

É de extrema seriedade ressaltar que a falta de participação da sociedade civil pelas barreiras que inviabilizam uma participação ativa, tornam as decisões menos transparentes e amplia o poder de influencia de grupos de interesse, sejam interesses econômicos, sejam interesses políticos que podem, por exemplo, influenciar a decisão de um projeto que tenha uma degradação significativa, ou seja, um projeto com impacto socioambiental expressivo.

Enfim, a participação se limita na maior parte das vezes ao direito de ser informado e de exprimir o ponto de vista, mas isso não basta, é preciso como foi discutido no decorrer do trabalho que a sociedade civil um agente ativo crítico. Por isso é necessário continuar estudando a participação social, para mostrar os fatores concretos e de manipulação nesses processos de participação, é preciso divulgar esse conhecimento para a participação evoluir em formas mais democráticas e não deixar retroceder, a sociedade precisa lutar por esse direito, e ter o poder de diálogo e decisão.

\section{Referencias Bibliográficas}

ALBERT, C. L.; ACOSTA P. S.; MARQUES D. P. Decision-making and stakeholders' constructive participation in environmental projects. Journal of Business Research. 2015.

AKBARI M, ASADI A, POURATASHI M, KALANTARI Kh. Determinants of public participation in management activities of local Parks. INTERNATIONAL Journal of Environmental Sciences. 2011

AMEZAGA. J. M.; LOSTAMAU, C.; MATURANA, H.; SOTO, M.; SOTO, G. OYARZÚN, J. Stakeholder participation within the public environmental system in Chile: Major gaps between theory and practice. Journal of Environmental Management. 2011

ASSUNÇÃO, F. A participação social no licenciamento ambiental na Bahia: Sujeitos e Práticas Sociais. Tese de Doutorado. (Universidade de Brasília), Centro de Desenvolvimento Sustentável, Brasília 2006.

BAVA, S. C.; SOARES, J. A. Os desafios da gestão municipal democrática. São Paulo: Cortez, 2003.

BARROS, J. Participação Popular em Belém. Tese de Doutorado, 2002 
BEICRLE, T. C.; CAYFORD, J. Democracy in Practice: Public Participation in Environmental Decisions. Resources for the Future. 2002

BHERER, L.; BREUX, S. The Diversity of Public Participation Tools: Complementing or Competing With One Another?. Canadian Journal of Political Science. 2012

BURNETT, M.; HILLS, P.; TSANG, S. WELFORD, R. Trust, Public Participation and Environmental Governance in Hong Kong. Environmental Policy and Governance. 2009.

CANTER, Larry. Participación pública en la toma de decisiones ambiental. In: CANTER, Larry. Manual de Evaluación de Impacto Ambiental: técnicas para elaboración de estudios de impacto. Madrid: Mc Graw Hill, Capítulo 16, 1998.

CARVAlHO, M. C. Participação social no Brasil hoje. São Paulo: Instituto Polis, 1998.

CAVALCANTI, C.; SCHLAPFER, F. Public participation and willingness to cooperate in common-pool resource management: A field experiment with fishing communities in Brazil. Ecological Economics. 2010.

CHUN, M. H.; NOR, W.; SAMAH, M. A. A.; SUlAIMAN, A. A Case Study on Public Participation for the Conservation of a Tropical Urban River. Pol. J. Environ. Stud. 2012

CRAIG, D. R.; HANSON, M. J.; HOURDEQUIN, M.; LANDRES, P. Ethical implications of democratic theory for U.S. public participation in environmental impact assessment. Environmental Impact Assessment Review. 2012

CHALliES, E.; DRAZKIEWICZ, A.; NEWIG, J. Public participation and local environmental planning: Testing factorsinfluencing decision quality and implementation in four case studiesfrom Germany. Land Use Policy. 2015

CENTA, J.; JURCZAKA, M. G.; KASZYNSKA. A. P. Emerging multilevel environmental governance - A case of publicparticipation in Poland. Journal for Nature Conservation. 2014

CHEN, M.; QIAN, X.; ZHANG. Public Participation in Environmental Management in China: Status Quo and Mode Innovation. Environmental Management. 2015

DALEY, D. M. Public Participation and Environmental Policy: What Factors Shape State Agency's Public Participation Provisions?. Political Science and Environmental Studies. 2008

DOUGLAS, L.; OZER, E. The Impact of Participatory Research on Urban Teens: An Experimental Evaluation. Springer. 2013

ENSERINK, B. KOPPENJAN, J. Public participation in China: sustainable urbanization and governance. Management of Environmental Quality: An International Journal. 2016

FAIRCHEALLAIGH, C. Public participation and environmental impact assessment: Purposes, implications, and lessons for public policy making. Environmental Impact Assessment Review. 2009

FREY, Klaus. A dimensão político-democrática nas teorias de desenvolvimento sustentável e suas implicações para a gestão local. Ambiente \& Sociedade, v.4, n. 9, 2 Sem. 2001.

FINSON, R.; TULER, S.; WEBLER, T. Competing perspectives on public involvement: Planning for risk characterization and risk communication. Health, Risk \& Society. 2005

GOHN, M. G. O protagonismo da sociedade civil: movimentos sociais, ONGs e redes solidárias. São Paulo: Cortez, 2005.

GU, H. NIMBYism in China: Issues and prospects of public participation infacility. Land Use Policy. 2015

IRVIN, R. A.; STANSBURY, J. Citizen Participation in Decision Making: Is It Worth the Effort?. Public Administration Review. 2004

HARTLEY, N.; WOOD, C. Public participation in environmental impact assessmentimplementing the Aarhus Convention. Science Direct. 2005. 
HOLDEN, M. Public Participation and Local Sustainability: Questioning a Common Agenda in Urban Governance. International Journal of Urban and Regional Research. 2011

KRUEGER, R.; TULER, S.; WEBLER, T. What Is a Good Public Participation Process? Five Perspectives from the Public. Environmental Management. 2001

KIKUCHI, T.; KOBORI, H.; NAKAMURA M.; SAKURAI R. Factors influencing public participation in conservation activities in urban areas: A case study in Yokohama, Japan. Biological Conservation. 2015

LAU, M. C.; TANG, B.;WONG, S. Social impact assessment and public participation in China: A case study of land requisition in Guangzhou. Science Direct. 2008

LAURIAN, L. SHAW, M. M. Evaluation of Public Participation The Practices of Certified Planners. Journal of Planning Education and Research. 2008

MARZLUFF, J. M. Public Participation in Environmental Research. BioScience. 2013

NASCIMENTO, E. P. do. Participação: entre o autoritário e o democrático. 1986.

NUNES, D. Por uma pedagogia da participação popular. Salvador: EAUFBA, 2006.

ROSOL, M. Public Participation in Post-Fordist Urban Green Space Governance: The Case of Community Gardens in Berlin. International Journal of Urban and Regional Research. 2010

SANTOS, R. F. de. Planejamento Ambiental: teoria e prática. São Paulo: Oficina de Textos. 2004.

SPES, M. Pomen okoljske ozavescenosti in sodelovanja javnosti za trajnostni razvoj. Razprave. 2008

SEXTON, K. Evolution of public participation in the assessment and management of environmental health risks: a brief history of developments in the United States. Journal of Public Health Research. 2013

VEIGA, B. Participação social e políticas públicas de gestão das águas: olhares sobre as experiências do Brasil, Portugal e França. Tese de Doutorado. (Universidade de Brasília), Centro de Desenvolvimento Sustentável, Brasília, 2007.

VILLAÇA, F. As ilusões do Plano Diretor. São Paulo, 2005.

Recebido em janeiro de 2017

Aceito em maio de 2017 